\title{
The Realization of Higher Order Thinking Skills in English School Nationally Standardized Examination at State Senior High School 6 Semarang
}

\author{
Nanang Narwianta ${ }^{1}$, Dwi Anggani Linggar Bharati ${ }^{2}$, Dwi Rukmini ${ }^{3}$ \\ \{ nanangsuranang@gmail.com ${ }^{1}$,dwi_anggani@mail.unnes.ac.id ${ }^{2}$, wiwidwirukmini@mail.unnes.ac.id ${ }^{3}$ \} \\ ${ }^{1}$ SMA Negeri 1 Membalong, Jl. Ahmad Yani km 52 Membalong, Belitung, Indonesia \\ ${ }^{2}$ English Education Department of Graduate School, Universitas Negeri Semarang, Indonesia \\ ${ }^{3}$ English Education Department of Graduate School, Universitas Negeri Semarang, Indonesia
}

\begin{abstract}
Higher Order Thinking Skills (HOTS) is a skill needed for the competitiveness in the 21 st century. HOT is realized in assessment program which one of its implementation in English school nationally standardized examnation. This study aims to explain the realization of HOTS and to explain the cognitive process dimension in English school nationally standardized examination. This research employed descriptive qualitative approach using an analysis card to analyze the realization of higher order thinking skills in English school nationally standardized examination test items. The study revealed that HOTS realized in listening, reading, and writing questions. The analyzing level is dominated students cognitive process dimension. This finding reveals that there is still much room for the variation of HOTS levels implemented all skills in English school nationally standardized examination. This study recommends modifying the the proportion of HOTS in four skills.
\end{abstract}

Keywords: Realization, Higher Order Thinking Skills, School Nationally Standardized Examination

\section{Introduction}

Based on the curriculum 2013, the purpose of learning English can be achieved by implementing higher order thinking skills. It is in line with the government that expects students to achieve various competencies by applying higher order thinking skills. These competencies are creative and innovative, communication skill, collaboration, and confidence. Higher order thinking skill is defined as the level of thinking where the process is done more than just repeating information or facts. Higher order thinking skills as a way of thinking at a higher level than memorizing or retelling something that is told by other people [1]. Furthermore, higher-order thinking skills are the ability to think that not only requires the ability to remember, but also higher capabilities [2]. Higher order thinking skills are student's abilities that are activated when students encounter unfamiliar problems, uncertainties, questions or dilemmas. Whereas in Bloom's revised taxonomy higher order thinking skills are specified in three-dimensional thinking consist of analyzing, evaluating and creating [3].

Higher order thinking skills should be implemented in the learning process and assessment program. Students should be trained and accustomed to higher order thinking skills during the learning process and an assessment program like the formative and summative test. 
Higher order thinking skills is not effective if it is not preceded in the learning process. Assessment of higher order thinking skills in curriculum 2013 is needed as an effort to improve the quality of learning and improve the quality of graduates. National examination and school nationally standardized examination as the summative test is regarded as the highlevel assessment program but because of the limitation of the time and budget not all of higher order thinking skills can be covered in school nationally standardized examination test items.

In school nationally standardized examination, learners are required the ability to work on higher order thinking skills questions. Every year the percentage of higher order thinking skills test items which are inserted in the national examination is improved. According to the regulation of the Minister of Education and Culture number 24, 2018 about national examination and school nationally standardized examination in academic year 2018/2019 there is approximately $10-15 \%$ of higher order thinking skills test items [4]. Therefore, higher order thinking skills should be prepared and inserted in school nationally standardized examination test items.

Several studies on higher order thinking skills test items conducted by Indonesian researchers. Febrina, Usman and Muslem investigate the HOTS questions in the reading comprehension tasks in the Bahasa Inggris SMA/MA/SMK/MAK textbook grade $11^{\text {th }}$ semester 1 published by the Ministry of Education and Culture. The result shows that HOTS questions in the reading comprehension tasks dominated the textbook [5]. Likewise expressed by Mahfuzah, Jufri, and Fitrawati who explain the students' ability in answering HOTS questions in reading and the mistakes made by the students in answering those questions. The result shows that the students' ability in answering HOTS reading questions was fairly good and the most frequent mistake was producing idea to solve problems [6]. Putra and Abdullah examine the HOTS questions in the last five years in English national examination. The result shows that the proportion of HOTS questions in English National Examination from 20132018 was insuffient [7]. Furthermore, Ahmad analyze the levels of the Barrett taxonomy reflected in English national examination test items academic year 2013/2014 and the consistency of the proportions of LOTS and HOTS. The result shows that questions asking LOTS still prevailed in English national examination items [8].

Those previous studies recommend that other researchers need to conduct studies in analysis of HOTS questions to see the realization of the higher order thinking and students thinking dimension to solve the HOTS items. Thus, in this study, the researcher is interested to conduct the research about the realization of the higher order thinking skills in English school nationally standardized examination.

\section{Methods}

This qualitative research purpose to explain the realization of higher order thinking skills in the English school nationally standardized examination The subject of this research is the English school nationally standardized examination of the academic year 2018/2019. The object of this study is the higher order thinking skills test items in English school nationally standardized examination. The researcher develops a tool called categorical higher order thinking skills, describe and analyze data based on the characteristics of higher order thinking skills in English school nationally standardized examination in the form of analysis card.

To gather all the information needed, the researcher collected all suitable documents that are available. The documents collected in this research were, the test paper and answer sheets 
of English school nationally standardized examination for senior high school in academic year 2018/2019 obtained from schools, and the English school nationally standardized examination blueprint from Board of Education National Standard.

To analyze higher order thinking skills on English School nationally standardized examination, several steps are done in analyzing data. First of all select the school nationally standardized examination paper test items. After selecting the document, the writer identifying and put into types of the question-based on Bloom`s Taxonomy. Then the data of higher order thinking skills were analyzed through analysis card. Finally, the writer analyzes and interprets the finding based on the data.

\section{Results and Discussion}

The researcher analyzed HOTS questions based on criteria according to Bloom's revised taxonomy. Higher-order thinking skills is three-dimensional thinking consist of analyzing, evaluating and creating. HOTS demand to do something about the facts. Learners must understand, conclude, connect facts with other facts and concepts, categorize, manipulate, and apply them to find new solutions to new problems encountered. In measuring students' highlevel thinking skills, a question is needed with indicators that meet the criteria for measuring HOTS students.

Table 1. The distribution of HOTS questions

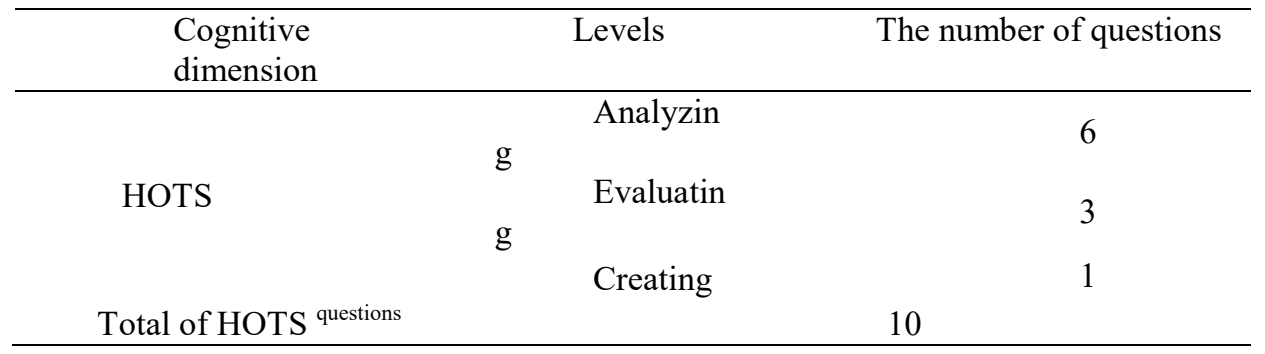

Data of the questions asking students' HOTS were obtained from the paper test of English school nationally standardized examination. In order to show how the data were analyzed, some part of the total data was chosen as an illustration. For this reason, some items of the English school nationally standardized examination are presented as an example. The HOTS question in the level of analyzing can be seen in figure 1. 


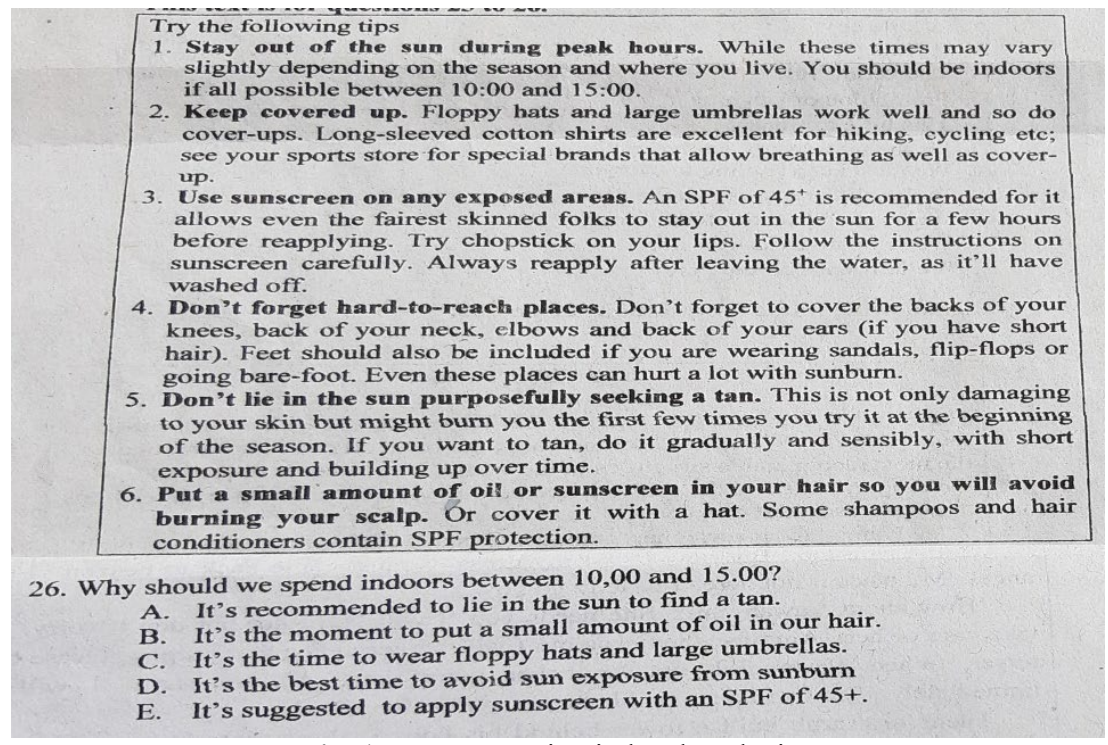

Fig. 1. HOTS question in level analyzing

From the example question above, the level of higher order thinking skills in the analyzing level, it means that to find the answer the students should breaking concepts into the part, determining how the parts relate to one another or to an overall structure or purpose. It is in line with the operational word that uses in the question "explain", to find out the answer explain the reason the students should read the whole text then breakdown the information and then find out the correlation of the complex material, in this case, the text is procedure in the form of tips. In the term of the depth of the knowledge level, the question categorized as strategic thinking/reasoning because here students explain information within the text and also how it affects the interpretation of the reading selection. Furthermore, the knowledge dimension of the question above is conceptual because the knowledge that needed to answer this question is knowledge of principle or generalizes the relation to present the systematic point of views about the subject matter.

The realization of HOTS question in the level of evaluating shown in figure 2. 
Im the cripple on the corner

You pass me on the street

I wouldn't be out here beggin'

If I had enough to eat

And don't think that I don't notice

That our eyes never meet.

I lost my wife and little boy

Someone crossed that yellow line

The day we laid 'em in the ground

Is the day I lost my mind

Right now I'm down to holdin'

This little cardboard sign.

taken from : http//www. metrolyrics

20. What is the message of that lyrics ?
A. We must keep smiling to everyone
B. We're all the same in God's eyes
C. We're good friends all the time
D. We're relatives as long life
E. We're friends all the time

Fig. 2. HOTS question in level evaluating

From the question above, the level of higher order thinking skills in the evaluating level, it means that to find the answer the students should making judgments based on criteria and standards through checking and critiquing. It is suitable with the operational word that uses in the question "evaluate", to find out the answer in this case the message of the song lyrics students should read the whole text then comprehend the meaning of the song lyrics and then find out the connotation or hidden meaning from the song lyrics to determine the message of the song lyrics. In the term of the depth of the knowledge level, the question categorized as extended thinking because here students gather, analyze, and evaluate relevancy \& accuracy then draw and justify conclusions. Moreover, the knowledge dimension in the reading question above is procedural because the knowledge of techniques and specific methods of a subject include knowledge that is broadly the result of disciplinary norms rather than knowledge directly a result of observation. This part of this type of knowledge generally describes how these fields or disciplines think and solve problems rather than the results of thinking or solving the problem.

Last but not least the realization of HOTS question in the level of creating can be observed in figure 3 . 


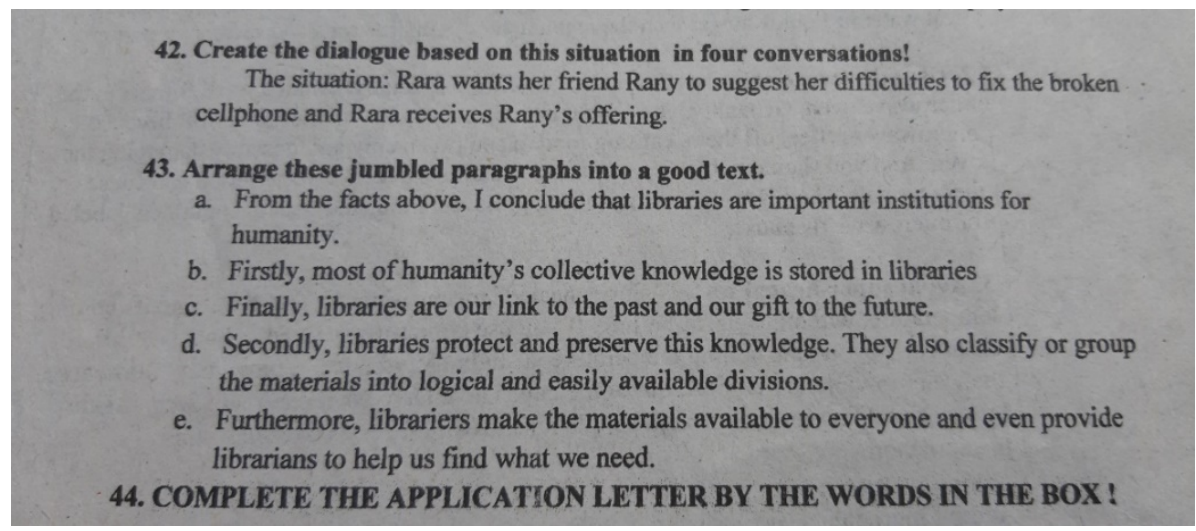

Fig. 3. HOTS question in level creating

The level of higher order thinking skills of the example question above is creating, it means that to find the answer the students should be able to pull together parts of knowledge to form a new whole and build relationships for a new situation. It is suitable with "create" as the operational word that uses in the question. To answer in this case create the dialogue based on the situation given students should mastery the expression about the situation in that case expression that used is expression giving suggestion. The students also relate the expression of suggestion with the situation to make the dialogue cohesive and coherence. In the term of the depth of the knowledge level, the question categorized as extended thinking because here students synthesize information across multiple sources or text then design a model to inform and solve a real-world, complex situation. Furthermore, the knowledge dimension of the question above is metacognitive because the students develop the knowledge about the strategy and thinking process to solve problems by finding solutions, planning, create a procedure to achieve a particular purpose, or produce something new.

The few distributions of the HOTS happen because the questions look much more complex than the LOTS. Therefore the test maker concern about the limitation of time provided for the student to work. It is supported by Airasian and Russel who said that the higher level questions often require the students to answer those questions. So that the English nationally standardized questions is dominated by LOTS [9].

Having higher order thinking skills in reading is important for the students because, in the reading activity, the students need to answer the reading questions at all levels of thinking. It is supported by the claims of Anasy stated that for the eleventh grade of senior high school students who will continue their study to the college or even for them who want to go to work, having higher order thinking skill is very important for preparing themselves to do their thinking in the real world [10].

Students of senior high school are demanded to be able to cope with the development of technology as well as the creative industry. It is in line with the claims of Larson and Miller said that most students are working on the lowest levels of thinking and teachers should prepare students with 21 st-century skills. They emphasize that teachers should encourage students to apply knowledge, analyze that knowledge in multiple ways, synthesize or create new knowledge, and continuously evaluate it [11]. In addition, Trilling and Fadel point out that there will be a rising demand of workers who can fill in the jobs that involve higher levels of knowledge and applied skills like expert 
thinking and complex communicating. Consequently, students need to sharpen their knowledge and insight, exercise their minds to think critically and learn to communicate effectively so that they can survive to deal with the needs 21 st-century [12].

\section{Conclusion}

Based on the findings, HOTS in English school nationally standardized examination is realized in 10 of 45 questions. The 10 HOTS questions is dominated by analyzing level. It means that the various levels of the HOTS needed to be enriched with more HOTS especially for evaluating and creating level. The few distributions of the HOTS happen because the questions look much more complex than the LOTS. Therefore the test maker concern about the limitation of time provided for the student to work. It is recommended that the test makers should modify the proportion variation of HOTS questions in English school nationally standardized examination. The test makers should consider the anxiety and worries of the student's failure in working the test. Then create alignment between the English school nationally standardized examination HOTS questions with the curriculum to ensure the reduction of LOTS level questions and increase the questions requiring analyzing, evaluating, and creating which belong to HOTS. 


\section{References}

[1] Thomas, A., \& Thorne, G.: How to increase higher order thinking: Retrieved from http://www.cdl.org/articles/how-to-increase-high-orderthinking. (2009)

[2] King, F. J., Goodson, L., \& Rohani. F.: Higher order thinking skills: definition, teaching strategies, assessment (Educational Services Program). (2010)

[3] Anderson, L. W., \& Krathwohl, D. (Eds.).: A taxonomy for learning, teaching, and assessing: a revision of Bloom's taxonomy of educational objectives. New York: Longman. (2001)

[4] The regulation of the Minister of Education and Culture number 24, about National examination and school nationally standardized examination. (2018)

[5] Febrina, Usman, B., \& Muslem, A.: Analysis of reading comprehension questions by using revised Bloom's taxonomy on higher order thinking skills (HOTS). Vol. 10, pp. 1-15. English Education Journal (EEJ) (2019)

[6] Mahfuzah, A., Jufri, \& Fitrawati.: Students' ability in answering reading questions with HOTS at SMA N 3 Bukittinggi. Vol.8, pp. 71-81. Journal of English Language Teaching, (2019)

[7] Putra, T. K., \& Abdullah, D. F.: Higher-order thinking skill (HOTS) questions in English national examination in Indonesia. Vol.11(1), pp. 145-160. Jurnal Bahasa Lingua Scientia, (2019)

[8] Ahmad, U. L.: Senior high school english national examination and thinking skills. Vol. 4, pp. 168-190. Beyond Words, (2016)

[9] Airasian, P. W., \& Russel, M. K.: Classroom assessment: concepts and applications 6th Ed. Boston: McGraw-Hill. (2008)

[10] Anasy, Z.: Higher order thinking skills (HOTS) in reading exercise. Vol. 3, pp. 51-63. TARBIYA: Journal of Education in Muslim Society, (2016)

[11]Larson, L. C., \& Miller, T. 21st century skills: prepare students for the future. Vol.47, pp. 121-123. Kappa Delta Pi Record, (2011)

[12] Trilling, B., \& Fadel, C.: 21st century skills: learning for life in our times. San Francisco: Jossey-Bass. (2009) 